\title{
Exergy analysis of day light using fuzzy logic controllers of Jordanian commercial buildings
}

\author{
Ali M Baniyounes ${ }^{1}$, Yazeed Yasin Ghadi ${ }^{2}$, Mazen Alnabulsi ${ }^{3}$ \\ ${ }^{1,3}$ Department of Architecture and Electrical Engineering, Applied Science Private University, Jordan \\ ${ }^{2}$ Software Engineering and Computer Science, Al Ain University, United Arab Emirates
}

\begin{tabular}{l}
\hline Article Info \\
\hline Article history: \\
Received Mar 3, 2020 \\
Revised Apr 26, 2020 \\
Accepted Jul 22, 2020 \\
\hline
\end{tabular}

Keywords:

Day light

Fuzzy logic

Illuminance

Intelligent building

Saving energy

\begin{abstract}
Saving energy and greenhouse gas emissions in commercial buildings become a very serious request of buildings' designers and engineering crew. The goal behind the current research is to high light and demonstrate the outcome of utilizing advance and intelligent building management system (IBMS) based in utilizing a fuzzy logic controller that allows the usage and the control of natural light (day light). The fuzzy logic controller (FLC) was sat to control the buildings dimming system while utilizing natural light which normally allows to add outdoors illuminance into the inside ones. This control system is significant mean technique that can be used in intelligent buildings commercial buildings, hence energy savings and consequently, greenhouse gas emissions reduction. The proposed control system relies on enumerating the outdoor and the indoor illuminance and allowing some addon controllers in order to put into effect a photometric computer that capable of comparing and tasking decisions to regulate rooms lighting fixtures. The article also demonstrates energy savings using this technique and then suggest proper markets for using this controlling system whether during the buildings' design stage, existing commercial buildings.
\end{abstract}

This is an open access article under the CC BY-SA license.

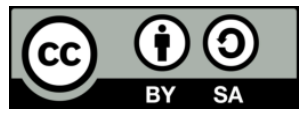

\section{Corresponding Author:}

Yazeed Yasin Ghadi,

Software Engineering and Computer Science,

Al Ain University,

Al Jimi, Near Al Ain Municipality, Al Ain-Al Jimi-Abu Dhabi, United Arab Emirates.

Email: yazeed.ghadi@aau.ac.ae

\section{INTRODUCTION}

Now a day's intelligent control systems in buildings and intelligent buildings become the center of attraction between developers, researchers and designers as a result of its capability to control, supervise and regulate energy consumption and its conservation strategies. Also, intelligent buildings depend on utilizing unconventional fuzzy logic control system that capable of using the most advance and state-of-the-art control systems in sequence to accomplish a comfortable indoors living whereas energy savings and consequently, minimizing negative impact on the environment. Utilizing fuzzy logic controller (FLC) in intelligent buildings management system (IBMS) develops and progresses real life occurrences as set-point of control input. The sets of real-life actions such as day-light use (natural light), ambient conditions, Occupancy density occurrence profile, Natural cooling and heating means, and hence, using surrounding atmosphere established on its outdoor temperature and humidity.

Commercial buildings are ranging between hospitals, Institutional buildings, hotels, governmental firms' offices and etc. All of those buildings acclimate daily occupants' events, tools and functions. In commercial buildings, indoor visual and thermal comforts are significantly important to keep indoor 
convenient working and living place and also to supply a health-giving indoor atmosphere for its occupants. According to [1] buildings' heating, ventilation and air-conditioning (HVAC) systems utilize near $40 \%$ of buildings' vas energy-usage. The second biggest consumer is lighting systems which accounts foe 20-30\%. Currently, in Jordan, electricity expenditure which feeds indoor and outdoor lighting fixtures is highly increased. Therefore, the Jordan's national electricity grid tackles the risk of overcapacity and overloading which may trigger service interruption and thus economic and environmental hazards [2].

The Jordanian electricity is generated by the means of burning conventional fossil fuel which known for its negative impact on environment and consequently, climate change which caused by greenhouse gas emissions [3]. Now a day, the international efforts focusing in reducing energy usage in commercial buildings have directed on reducing energy used by HVAC systems and lighting fixtures besides the effecive exploitation of solar energy. IBMS can alter and control time of using artificial lighting fixture illuminance [4]. FLC can be utilized to control lighting fixtures and day-light together in order to minimize the expenses of artificial lights use. Based on [5], FLCs concerning lightings control systems are able to reduce lightings' energy expenditure by almost $30-50 \%$ in current buildings and by nearly $25-35 \%$ in freshly constructed buildings.

FLCs that are used in IBMS accurately capable of adjusting and adding to the luminance of natural light to the indoor luminance alongside with luminance resulted from artificial lights and in certain times, make the main source of illuminance is the daylight illuminance which is normally supported by a secondary artificial illumination source e.g. electric lighting fixture. As natural light denotes a dynamic supplier of illuminance, artificial electric lighting fixtures control systems is necessary to combine and arrange the lighting systems while changing in lighting conditions.

Vast number if scholars and developers are focusing in reducing energy consumption of commercial buildings whose normally thought-out energy reduction via certain construction specification $e$.g. functional management, means [6] alongside with thermal comfort means e.g. HVAC system and its efficiencies and operations [7-10]. Energy conservative, reducing of negative impact of greenhouse-gas (GHG) emission on the environment and influence on indoor atmosphere have been analyzed and assessed by several of simulation and experiment research. Researches' results exhibited that the natural light and electrical illuminaces can be integrated into IBMS system to guarantee light adequacy stays suitable at all times and is automatically adjusted for different weather and seasons [11].

A mean of determining the understanding of a domestic occupants to external temperature and the action of both sun set and sun rise and then utilizing allocated data to adjust the execution of occupants' arrangement and electric light technique which have been established. The significance of various types for that kind of system has been evaluated by Beckel et al. [12]. As well as, Martirano et al. [13] recommended a simulated study of an intelligent office-room, combined by dynamic sheltering, electric-lighting and air conditioning control system.

Countless present means are able to foresee guesstimate illuminance-set in different locations within a space, taking into accounts its dimensional characteristics, its global positioning, the solar standing, the exterior features and the climate situations [14]. Nevertheless, there are few researches that specialize in intelligent commercial buildings in Jordan.

The aim of this study is to show the way of using FLC controlling system to guess indoor and outdoor illuminance combination rule in order to save energy. In this study, an FLC model which is able to picture the associations between the system inputs and outputs is designed and established. The model is able to quantify the outdoor and the indoor illuminance permitting add-on controllers to execute a photometric analysis and comparison in order to decide the dimming of artificial electric fixtures. Rather more, the article evaluates the energy savings due to the usage of natural light by using FLC systems in IBMS and suggests proper markets of this process as well throughout the proposal phase of a commercial-building, also the proposal can be carried out later the building formation.

\section{ARTIFICIAL LIGHTINGS CONTROL}

Electric lighting fixtures control systems, and the means of controlling artificial lighting fixtures, supplies proper illuminance combination considering energy savings and reduction of operating costs. Intelligent energy management system (IEMS) carry out the task of energy savings throughout illuminance reduction or by reducing artificial lights operational time. The most important element in lightings' control system is consideration of the occupants' physiological aspects e.g. , a twenty years old individual requires a $1 / 3$ less light intensity than sixty years old person to execute the same task [15]. The majority of literature studies recommended that majority of lighting control systems depend on the below techniques:

- Tenancy density and resident Count property: wherever illumination is turned ON/OFF based on residents' call. 
- Time of Work: when light-fixtures are switched ON/OFF established according to timetable.

- Natural light collecting (the utilization of daylight to light up the place).

- Demand reaction: here, required electric energy feeding electric fixtures is minimized based on equipment limitation aspects

- Adaptive advantage: here light strength set are lower during night-time than its strength set throughout day-time.

In general, natural light adaptive controllers consists of two aspects [16]: The control of day-light as the source of light of a space, and the hand is considering the electric lighting is output. The first option is limited due to it is sometimes is not able to present adequate quantity and quality of natural light inside a space; the other mean is able to perform energy savings while maintain the uniform light where natural light is inadequate. Globally, the main source of lighting in commercial is Fluorescent lighting fixtures with a color-temperature range between $3-4.500 \mathrm{k}{ }^{\circ}$ Kelvin which similar to the color of natural light [16, 17].

The control of natural light (daylighting) depends on on constant dimming strategy which allow residents setting lighting illuminance levels and supply adaptable system in comparison to conventional (step-dimming) control system. Intermittent dimming tracks the day-lighting arrangement thoroughly, it is sometimes more suitable to resident, and could save more energy, mainly in spots with high varying over cast. Continuous dimming as well as counters to changes in illuminance output as a reason of dirt reduction on light fixtures, and lamp lumen decreased as a reason of the lamp age $[15,17]$.

The sustainable finidngs throughout literature theory has attracted interest in natural light (daylighting); alongside energy reductions as daylight deliver greater sense of comfortless. However, the huge attention of light engineers for this technique is depending on its energy reduction potential: a building that use daylight will need lower electric lighting fixtures throughout day hours, mostly in sunlit places.

\section{FLC CONTROLLING DAY-LIGHTING}

Day-light is a rich source of illuminance and the difference in natural and day light is due to seasons variation which depends on space geographical location e.g. latitude, longitude and also sky conditions. Several sky-light stages might be carried out under the same sun-light situations, and, similar thinking during the sky conditions stays unchanged. Also, the range of sun illumination possibly will be maximized due to transient turbidity filter due to particles scattering over the sun radiation path. Consequently, any estimate system must be flexible to permit multivariate variation which illustrate the sequence of sun-light and skylight [18]. Today, control strategies have been advanced rapidly and have happened to be a very efficeint mechanism within the trades. Nevertheless, as a reason of beforehand mentioned points, conventional control systems, that is rely on mathematical models, have exposed their constraint in controlling day lighting. Therefore, and because of using unplanned conditions and accessibility of natural light and vagueness and variation of its features, FLC have benefits over regular control methods and assured to be enhance key.

FLC systems the characterized by its ability of reducing complication and it is accomplished by subjective evaluation of the existing data. Mathematical values are defined using fuzzy sets, anyplace mathematical values are linked to mankind thinking. The quality of FLC can be dignified only with related era e.g. adjustment, capability, effectiveness and comfortable during usage. Control codes of FLC attest to supply well strength and effectiveness during more troubled nonlinear and time changing working situation compared to conventional proportional-integral-derivative controller PID. A significant advantage of the FLC plan is the key element that drive straight using human-factors and perceptive. It depends on a semantic standard, that can be states using a group of IF-commands rules, IF THEN commands.

\subsection{Fuzzy based-controller}

Fuzzy based-control systems comprise of input data level, a handling level, and also yield stage. Input stage records readers or additional recorded inputs, e.g. switch-buttons and dimmers to the appropriate membership rolls and right adjustment. The handling level increases linked instruction and creates outcome for every single instruction, then the following of the merging the effects of this function. The output level changes the merged outcome to precise controlled command [19].

The building indoor of fuzzy based-control system includes the following 4 basic units:

- Fuzzification unit: here the unit changes the sharp input-data functions to fuzzified group to be consistent with the fuzzy-data commands of the progression situation essential to the implication module.

- Knowledge unit: it comprises of dual tasks; a task stations which illustrate the control timetable also an information set stage which contains the organization of the fuzzification modules indicating the semantic circumstances utilized in the operation. 
- Inference module: the module produces fuzzification and thus operational behaviors through implementing the rules in the information module to the existing procedure status.

- Defuzzification unit: changes the fuzzy-based controller act produced by the interference module to a crisp data quantity which can be depleted to run the regulators.

\subsection{Natural light fuzzy based-controllers}

The natural light FLC utilize uses as digital circuit of lightings' system adjustment and constant electronic reducing stabilities adjusted by using 110-220 volts analog signs as power controlling [19]. The stabilizer obtains a signal as of the controller and then variates the electric-current running through the light fixture, thus attaining a regular adjusted diminution in the light fixture amount produced. The features of controlled signs imitate the period and level of the variation in the electric-current and succeeding light fixture production. Utmost market available regulators switches for control of those light fixtures are electric rapid-ignition or automatic -start switches, most of regular light fixtures worked using this switches element BIPIN pedestals normal of RAPID-START light fixtures. By means of the detecting tool, unlike sort of photosensitive tools, market-available, could be employed. A model is a class room with $20 \times 15 \mathrm{~m}$ dimensions, the interior of the building hanged light fixtures structure, intended by usinf a software called DIALUX; comprises of 50 luminaires containing two 60WT18 regular fluorescent fixtures. The group attached in six rows of 6 units, like during working time operate part of the space, and reassure an acceptable light intensity standard of 490 lux $[19,20]$.

A significant mission involves appropriate collection of controlled parts; a controlled part is a set of fixtures or single fixture in luminaire which adjusted by one sign. The purpose in developing a controlled zones and parts is in order to outline zones which receives a constant quantity of natural light at particular duration and hence, reliable light standards requirement [20-25].

\section{RESULTS AND DISCUSSIONS}

The fuzzy based control system is suggested so it planed and utilized in Alkhawarezmi building the faculty of engineering building, at applied science private university which is located in Amman, Jordan as shown in Figure 1.

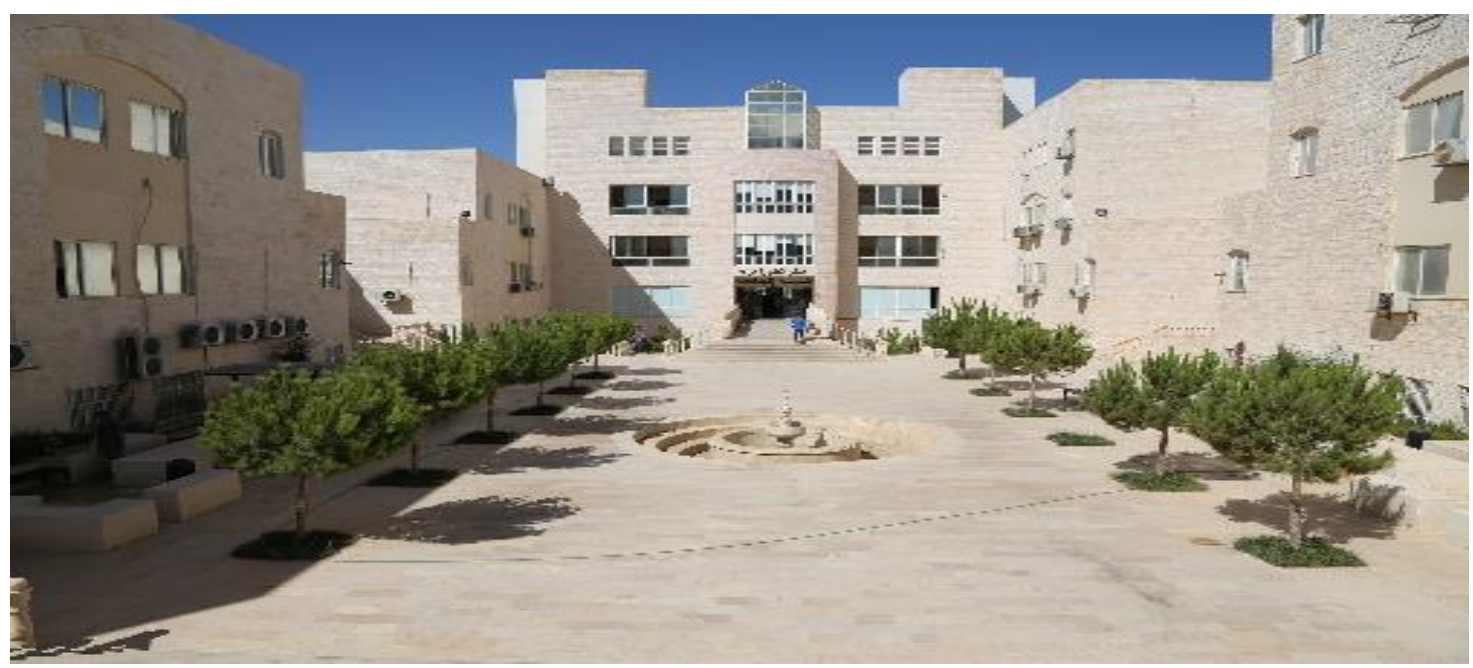

Figure 1. Alkhawarezmi building; at applied science private university campus

Figure 2 displays the engineering building's total lighting energy usage at $100 \%$ occupancy during a hole ( 24 hours). It has been noted that, the building's electricity usage is nearly $5 \mathrm{kWh}$. The building's maximum lighting electricity demand is ranging between $7 \mathrm{pm}-7 \mathrm{am}$. The minimum lightings demand was happening from $7 \mathrm{am}-5 \mathrm{pm}$ at nearly $1.1 \mathrm{kWh}$.

The suggested natural light fuzzy based-controller would be capable to utilize 4 sensors: occupants count system, activity and motion detective system and lighting intensity sensor, constantly automatic dimming switch for each fixture light intending the way of controlling lighting fixture yield, as well as a fuzzy based control system; the lighting level sensor are positioned in the controlled area of the place to 
represent the controlled command for the suggested control technique, installed to a fuzzy based control system. Thus, this article is a simulated based control system and all values which could originate from detector have been substituted by buildings evaluated information utilizing the software of DIALUX and MATLAB software package.

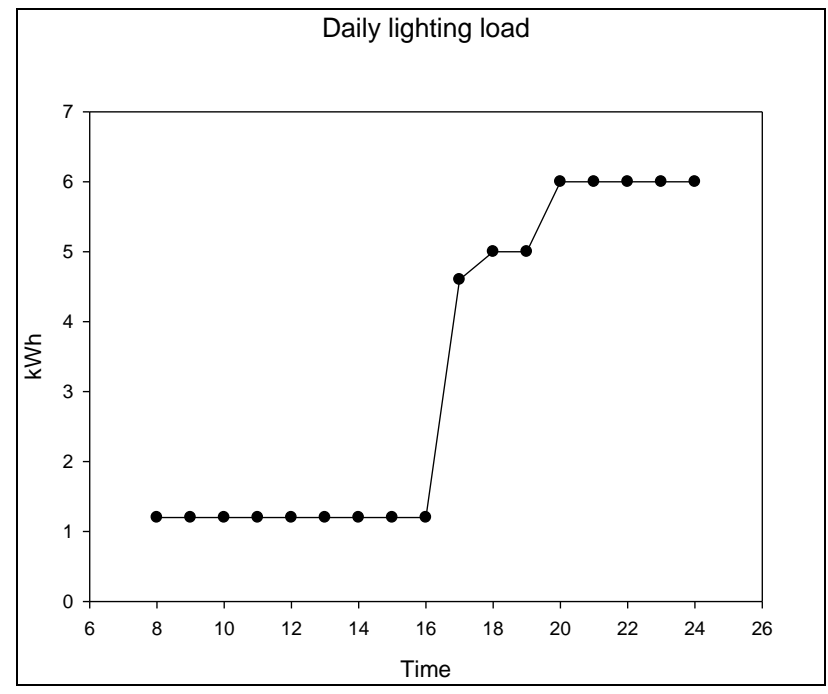

Figure 2. Alkhawarezmi building's lighting demand.

The input semantic adjusted data of the fuzzy based control system are the adjusted of the light intensity calculated by the 3 light intensity detectors where the output's function is the adjusted of the control sign delivered to Automatic switch in the regulated areas. Each linguistic adjustable has fuzzy quantity data with triangular membership relationship, as shown in Figure 3 as it demonstrates the inputdata and Figure 4 while the figure shows the output.

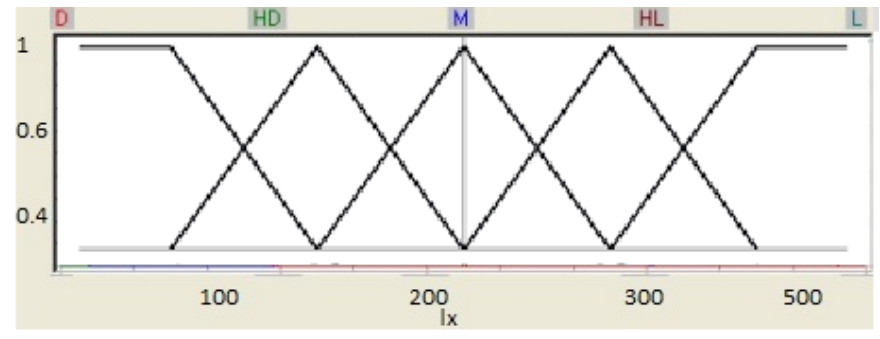

Figure 3. Fuziffication set input

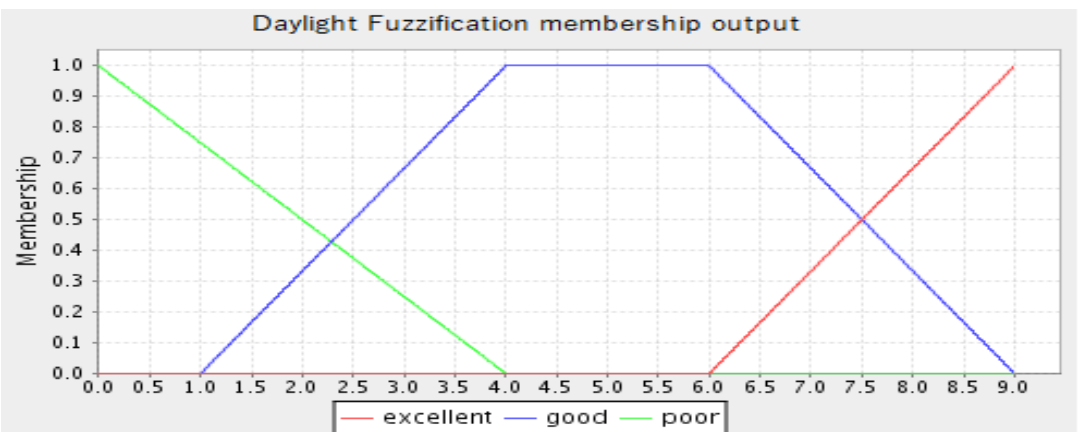

Figure 4. Fuzzification membership output 
Considering input data as demonstrated in Figure 3, D embodies black, HD embodies semi dark, M embodies adequate, HL embodies semi-light and L embodies light. The control system will relate to the output figure which it then resolves the utilization of natural light areas and duration appropriateness depends on outcome as shown in Figure 4. Employing member ship data set the light intensity quantity is offered through the suggested fuzzy based controller beneficial quantity and quality of light intensity associated with a substantial energy reduction.

Natural light has a large hopeful energy-reduction significance and became an appealing substitute to regular artificial-electric light fixtures. Conventional controllers, which depends on constant dimming, ignite few problems to set its performing to instant variations in natural-light relying on season, geographical positioning, and sky conditions. Noting that, the mention facts, fuzzy based controllers is able to perform suitable problem solving in establishing of natural-light, a dilemma which are not able to be represented by using mathematic models due to the lack of information's availability, incompetence, or difficult to handle. The suggested controller utilizes 4 detecting tools (e.g. Head counting/activity detection device and 3 light intensity level detection devices), permanent automatic dimming switch for each light fixture intending controlling light fixtures yield, and fuzzy based control system. Available information acquired by software that ensure the accuracy of the suggested tool.

\section{CONCLUSION}

Intelligent smart places and buildings and buildings' smart controllers are able to reduce energy by the mean of employing a group of commands that depends on surrounding day conditions $e$.g. the utilizing of natural light, climatic information, solar irradiance, occupancy level and much more. Based on the above, the study highlights the usage of fuzzy based controllers and hence, providing visual comfort and suitable light intensity. This article at the start outlined the problem, wherever energy-usage, comfortness and the controlling of the systems are the means of process. Next the article offered electric-current and regular controlling mechanism and also mentioning its problems associated with it. At last, the article established few smart controlling mechanisms in order to add on a natural light within lighting fixtures. The continuous development of buildings controlling mechanisms currently are essential to reduce energy and to the reduction of greenhouse gas emissions on the environment.

\section{REFERENCES}

[1] Baniyounes, A.M., et al., "An overview of solar assisted air conditioning in Queensland's subtropical regions, Australia," Renewable and Sustainable Energy Reviews, vol. 26, pp. 781-804, 2013.

[2] Baniyounes, A.M., et al., "Comparison study of solar cooling technologies for an institutional building in subtropicnd, Australia,” Renewable and Sustainable Energy Reviews, vol. 23, pp. 421-430, 2013.

[3] Meehl, G.A., et al., "Global climate projections," Climate change, vol. 3495, pp. 747-845, 2007.

[4] Rea, M.S., The IESNA lighting handbook: reference \& application, 2000.

[5] DiLouie, C., Advanced lighting controls: energy savings, productivity, technology and applications, The Fairmont Press, Inc, 2006.

[6] Norton, D.I., "Elementary school utilizes solar design techniques and groundwater cooling system for energy efficiency," ASHRAE Journal, vol. 37, no. 3, pp. 50-52, 1995.

[7] Rosenbaum, M., “A green building on campus,” ASHRAE Journal, vol. 44, no. 1, pp. 41-44, 2002.

[8] Seppänen, O.A., W.J. Fisk, and M.J. Mendell, "Association of Ventilation Rates and CO2 Concentrations with Health and Other Responses in Commercial and Institutional Buildings," Indoor Air, vol. 9, no. 4, pp. 226-252, 1999.

[9] Harriman, L., et al., "Evaluating active desiccant systems for ventilating commercial buildings," ASHRAE Journal, vol. 41, no. 10, pp. 28-37, 1999.

[10] Christopher, S., "Ventilation in the commercial environment," ASHRAE Journal, vol. 41, 10, pp. 73-76, 1994.

[11] Wang, Y. and P. Dasgupta, "Designing an adaptive lighting control system for smart buildings and homes, in Networking, Sensing and Control (ICNSC), 2015 IEEE 12th International Conference on, IEEE, 2015.

[12] Beckel, C., et al., "Automated Customer Segmentation Based on Smart Meter Data with Temperature and Daylight Sensitivity, in Proceedings of the 6th IEEE International Conference on Smart Grid Communications (SmartGridComm 2015), IEEE, Miami, FL, USA. 2015.

[13] Martirano, L., et al, "Simulation and sensitivity analysis of a fuzzy-based building automation control system," in IEEE Industry Applications Magazine, vol. 22, no. 2, pp. 1-7 IEEE Industry Application Society Annual Meeting, 2014.

[14] da Fonseca, R.W., E.L. Didoné, and F.O.R. Pereira, "Using artificial neural networks to predict the impact of daylighting on building final electric energy requirements. Energy and Buildings," vol. 61, pp. 31-38, 2013.

[15] Marzband, M., et al, "Energy management system of hybrid microgrid with energy storage," in 9th World Energy Systems Conference: towards sustainable and integrated energy systems: WESC 2012: June 28-30 2012, Suceava, Romania. 2012. 
[16] Maamari, F. and M. Fontoynont, "Use of IEA-SHC Task $21 \mathrm{C}$ benchmarks to assess performance of Lightscape 3.2 in daylighting calculations," in Lyon, France, Proceedings of EPIC conference. 2002.

[17] Cziker, A., M. Chindris, and A. Miron, "Fuzzy controller for indoor lighting system with daylighting contribution," in ELECO'2007 5th international conference on electrical and electronics engineering. 2007.

[18] DiLouie, C., "Good controls design key to saving energy with daylighting," Lighting Controls Association, 2005.

[19] Cziker, A., M. Chindris, and A. Miron, "Fuzzy controller for a shaded daylighting system," in Optimization of Electrical and Electronic Equipment, 2008. OPTIM 2008. 11th International Conference on. 2008. IEEE.

[20] Cziker, A., M. Chindris, and A. Miron, "Implementation of a lighting control system based on fuzzy logic," in Information and Control in Power Systems, vol. 40, no. 8, pp. 135-140, 2007.

[21] Shaltout AM, Shalaev VM, Brongersma ML, "Spatiotemporal light control with active metasurfaces," Science, vol. 364, no. 6441, 2019.

[22] Li H, Huang Z, Lang Y, Wang X, Zhu H, Shen Z, Guan H, Hong J, Gui X, Qiu W, Lu H., "Broadband all-lightcontrol with WS 2 coated microfibers," Optics express, vol. 27, no. 9, pp. 12817-12831, Apr 2019.

[23] L. Bhukya, A. Annamraju and N. Srikanth, "Fuzzy Logic Approach Based Novel Frequency Control Strategy by Wind Turbine Generator in a Wind-Diesel Autonomous Microgrid," 2019 IEEE 1st International Conference on Energy, Systems and Information Processing (ICESIP), pp. 1-6, Chennai, India, 2019.

[24] Bhukya L, Nandiraju S, "A novel photovoltaic maximum power point tracking technique based on grasshopper optimized fuzzy logic approach," International Journal of Hydrogen Energy, vol. 45, no. 6, pp. 9416-9427, 2020.

[25] Kirimtat, Ayca, et al., "Multi-objective energy and daylight optimization of amorphous shading devices in buildings," Solar Energy, vol. 185, pp. 100-111, 2019. 